\title{
CONVERGENCE ESTIMATES OF CERTAIN q-BETA-SZÁSZ TYPE OPERATORS
}

\author{
RANi YADAV AND MAN Singh BENIWAL
}

Abstract. The applications of $q$ calculus in operator theory is an active area of research in the last two decades. Several new $q$-operators were introduced and their approximation behavior were discussed. This paper is extension of the paper [South. Asian Bul. Math. (36) (2012), 343-352]. We propose here the Stancu variant of $q$-Beta-Szász type operators. We estimate the moments and also establish direct results in terms of modulus of continuity.

Mathematics subject classification (2010): 41A25, 41A30.

Keywords and phrases: $q$-Beta-Szász type operators, $q$-integers, $q$-factorial, $q$-exponential function, modulus of continuity, weighted approximation.

\section{REFERENCES}

[1] A. Aral, A generalization of Szász-Mirakkyan operators based on q-integers, Math. Comput. Model. 47 (9-10) (2008), 1052-1062.

[2] A. Aral And ViJay GuPta, q-derivatives and applications to the $q$-Szasz Mirakyan operators, Calcolo 43 (3) (2006), 151-170.

[3] A. Aral And V. Gupta, On q-Baskakov type operators, Demons. Math. 42 (1) (2009), 109-122.

[4] A. Aral And V. Gupta, On the Durrmeyer type modification of the $q$ Baskakov type operators, Nonlinear Analysis: Theory Methods Appl. 72 (3-4) (2010), 1171-1180.

[5] A. Aral, V. Gupta And R. P. Agarwal, Applications of q-Calculus in Operator Theory, Springer, (2013).

[6] C. Atakut And I. BuyukyazICI, Stancu type generalization of the Favard-Szász operators, Appl. Math. Lett. 23 (12) (2010), 1479-1482.

[7] I. BuyUKYAZICI, Approximation by Stancu-Chlodowsky polynomials, Comput. Math. Appl. 59 (1) (2010), 274-282.

[8] I. BUYUKYAZICI AND C. ATAKUT, On Stancu type generalization of $q$-Baskakov operators, Math. Comput. Model. 52 (5-6) (2010), 752-759.

[9] R. A. DeVore and G. G. Lorentz, Constructive Approximation, Springer, Berlin (1993).

[10] A. D. GAdZhiev, Theorems of the type of P. P. Korovkin type theorems, Math. Zametki 20 (5), (1976) 781-786. English Translation, Math. Notes 20 (5-6) (1976), 996-998.

[11] V. GuPTA, Some approximation properties on q-Durrmeyer operators, Appl. Math. Comput. 197 (1) (2008), 172-178.

[12] V. Gupta, T. Kim, J. Choi And Y-HeE KIM, Generating functions for q-Bernstein, q-MeyerKonig-Zeller and q-Beta basis, Automation, Computer, Mathematics 19 (1) (2010), 7-11.

[13] V. Gupta AND G. S. SRIVASTAVA, Convergence of derivatives by summation-integral type operators, Revista Colombiana de Mate. 21 (1) (1995), 1-11.

[14] V. Gupta And R. YAdAV, Some approximation results on q-Beta-Szász operators, South. Asian Bul. Math. 36 (2012), 343-352.

[15] T. KIM, New approach to q-Euler polynomials of higher order, Russian J. Math. Physics 17 (2) (2010), 218-225.

[16] T. KIM, Note on the Euler q-zeta functions, J. Number Theory 129 (7) (2009), 1798-1804.

[17] T. KIM, On p-adic q-l-functions and sums of powers, J. Math. Anal. Appl. 329 (2) (2007), 14721481. 
[18] A. LuPAS, A q-analogue of the Bernstein operator, in Seminar on Numerical and Statistical Calculus (Cluj-Napoca, 1987), pp. 85-92 Univ. Babes-Bolyas, Cluj.

[19] G. M. PHILLIPS, Bernstein polynomials based on the q-integers, Ann. Numer. Math. 4 (1997), 511518. 